\title{
New Psychoactive Substances: A Public Health Issue
}

The recreational drug scene has evolved dramatically over the last decade with the emergence of new psychoactive substances (NPS) supplementing rather than replacing the known drug repertoire. NPS are natural and synthetic recreational molecules, which mimic the effects of traditional drugs of abuse (TDA) (e.g. cocaine, amphetamine and ecstasy), yet they are not internationally controlled under the United Nations 1961 and 1971 conventions. The wide prevalence of NPS and complex nature inherent in NPS pose public health risks and represent great challenges to policy-makers, front-line staff and healthcare professionals (HCPs). Evidence shows that NPS have caused global problems, short and long-term health harms and they are "more than a one night wonder" (Chatwin et al., 2017).

NPS are characterised by a complex life-cycle. They are initially synthesised in bulk by chemical companies based in China and India; shipped by air or sea to Europe; sold directly in the illicit drug market or cut and packaged as 'research chemicals', food supplements or branded products. These labels support the covert marketing techniques undertaken by clandestine chemists and circumvent international legislation. NPS are sold online or in headshops (EMCDDA-Europol, 2016). They first appear on the deep web targeting NPS wholesalers, then the surface web via professional-like websites backed up with multi-buy deals (Corkery et al., 2017). During the first phase, the drug is mainly purchased and consumed by psychonauts (explorers of mind-altering activities using new NPS), who share their experiences on drug fora. This is followed by a displacement or substitution of a less popular NPS, death or birth of a new NPS (Corkery et al., 2017). Unlike pharmaceuticals, NPS are not produced in line with good manufacturing practices (GMP) or any type of quality assurance or clinical testing. They are tested directly on the consumer.

NPS epidemic cycles (Rose et al., 2015) evidence their prevalence among all age groups and defined societal sectors such as school and university students, MSM (men who have sex with men), heroin injectors, prisoners and music festival goers (Guirguis et al., 2017a). Their wide popularity is believed to be due to their perceived 'legal' status, potential for new experiences and desirable effects (e.g. increased libido, euphoria) wide availability, relative cheapness, and lack of detection (Guirguis et al., 2017b). The umbrella of NPS has recently widened (>740 NPS) (UNODC, 2017) to include not only newly invented drugs but re-emerging failed pharmaceutical patents, diverted use of prescription-only, pharmacy-only and over-the-counter 
medicines and the so-called 'smart drugs' (cognitive, image, mood \& behaviour and sexual enhancers; and muscle and weight-loss drugs).

NPS pose significant public health concerns. Their complex pharmacological profile results in a combination of psychoactive effects (e.g. both cocaine and MDMA-like effects) previously only possible through cocktails of TDA. Clinical challenges faced by HCPs include the different routes of administration of NPS, inconsistent content in and potency of branded products, unclaimed active ingredients, frequent dosing, poly-drug use, presence of complex mixtures (Home Office, 2014), lack of knowledge of their toxicodynamics and toxicokinetics, different formulations and unknown knowledge of the consequences of chronic use. On presentation to emergency departments users rarely know what they have taken, which reduces the effectiveness of subsequent clinical interventions.

Another major challenge to HCPs is how to categorise NPS, which often leads to the adoption of a symptom-management approach, particularly with the lack of information via professional databases such as Toxbase (Gilani, 2016). Management should preferably be tailored to patients and supported by a multi-disciplinary approach. Regular users with problems of polydrug use may also suffer from a dual diagnosis i.e. an addiction problem associated with psychiatric disorders. Users may also suffer from secondary issues e.g. cellulitis resulting from injecting NPS. Available classifications such as those suggested in the NEPTUNE guidelines (Abdulrahim \& Bowden-Jones, 2015) and the Drug Wheel (Adley, 2017) offer a great support to HCPs, yet a regular update is necessary to map the new NPS on the drug scene. Limitations also include the ability of these tools to classify NPS from their complex names e.g. discriminating between the opioid U-47,700 and the classical cannabinoid HU-210. Another challenge faced by HCPs is that NPS fall outside the drug monitoring systems run by public health agencies (Evans-Brown et al., 2014) and this is particularly observed when non-regular users, who do not consider themselves as 'drug users' present to sexual or mental health services. Poor presentation to health services is also caused by the help received from peers on drug fora, stigma and lack of awareness or education.

In order to offer appropriate harm reduction advice, pharmacists and other HCPs need to know the following about NPS. They should be familiar their: 1) Chemistry: different NPS categories may have similar substructures. Knowledge of backbones may enable their classification and identification. In some cases, subcategories/ subfamilies have similar substructures such as with SCRAs (synthetic cannabinoid receptor agonists). 2) Pharmacology: the pharmacology of 
NPS has been explored in the literature (Schifano et al., 2015). HCPs should be able to recognise whether an NPS is an amphetamine-like, ecstasy-like, cocaine-like or opioid-like because this assists in treatment decisions. However, due their often multiple pharmacological effects, this makes them difficult to manage. 3) Duration of action: knowledge on the duration of action is important as those with short duration of action may lead to frequent dosing, leading overdosing and/or fatality, and is also important in detention to avoid death by withdrawal. 4) Routes of administration: These includes snorting, ingesting, slamming (gay injecting), bombing (rectal administration), smoking, liquid inhalation or vaping and knowledge of these informs bioavailability. 5) The formulations available: These include liquids, powders, tablets, capsules, herbs, herbal extracts and resins, herbs sprayed with synthetic NPS, seeds and oils. 6) Physical and psychological effects: a typical example is to discriminate between NPS-induced psychosis (self-limiting) and a diagnosis of schizophrenia. 7) Legislation in the UK (TSO, 2016; Guirguis \& Laurence, 2017). 8) Harm reduction advice: knowledge of what individuals are taking, dosage: it is important to advise users that the same dose of the same NPS that they purchased from the same website may have different content/ potency, unpredictable effects, mixing NPS with other substances can have detrimental effects because interactions are not known, known interactions between NPS and POMs e.g. antiretrovirals (Abdulrahim \& Bowden-Jones, 2016; Schifano et al., 2015) and effects of NPS on driving and operating machinery.

Recommendations suggest that HCPs should be proactive and respond appropriately to public health, social and safety risks (Gilani, 2016). This can be implemented by opportunistically detecting NPS use and capturing prevalence and patterns of use via detailed initial assessment and efficient drug history taking. It is crucial to adopt holistic approaches for prevention and harm reduction, counsel patients on the safe use of drugs to reduce health risks (e.g. bloodborne infection, hepatitis $\mathrm{C}$, etc.), educate and signpost them to sources of information on NPS, identify high-risk behaviours and share information with multidisciplinary HCPs. Research is needed to keep pace with the continuous emergence of NPS and to develop evidence-based guidelines for the management of acute and chronic NPS use. Post-marketing surveillance processes should enable the detection of the abuse potential of POMs (Schifano et al., 2016). Pharmacists should be able to identify and categorise the drugs, risk assess appropriately and raise awareness about high-risk NPS among users, particularly those on opioid maintenance treatment. At a national level, recommendations suggest that treatment providers need to offer new services tailored to NPS users rather than TDA users (Owen-Bowden et al., 2016). 


\section{References}

Abdulrahim D, Bowden-Jones O. 2015. Harms of synthetic cannabinoid receptor agonists (SCRAs) and their management. Available at: http://neptune-clinical-guidance.co.uk/wpcontent/uploads/2015/03/NEPTUNE-Guidance-March-2015.pdf Accessed 06 July 2017.

Abdulrahim D, Bowden-Jones O. 2016. Novel Psychoactive Treatment UK Network NEPTUNE, Guidance on the Management of Acute and Chronic Harms of Club Drugs and Novel Psychoactive Substances. Available at: http://neptune-clinical-guidance.co.uk/wpcontent/uploads/2016/07/Synthetic-Cannabinoid-Receptor-Agonists.pdf Accessed 06 July 2017.

Adley M. 2017. The drug wheel, Available at: http://www.thedrugswheel.com/downloads/TheDrugsWheel_2 0 2 2 _colour.pdf Accessed 06 July 2017.

Chatwin C, Measham F, Sumnall H. 2017. New drugs, new directions? Research priorities for new psychoactive substances and human enhancement drugs. International Journal of Drug Policy. 40: 15. DOI: 10.1016/j.drugpo.2017.01.016.

Corkery JM, Orsolini L, Papanti D, Schifano F. 2017. From concept(ion) to life after death/the grave: the 'natural' and life cycle(s) of novel psychoactive substances (NPS). Human Psychopharmacology: Clinical and Experimental. 32:e2566. DOI: 10.1002/hup.2566.

EMCDDA-Europol. 2016. EU drug markets report. In depth analysis. Luxembourg: United Nations. Available at: http://www.emcdda.europa.eu/system/files/publications/2373/TD0216072ENN.PDF Accessed 05 July 2017.

Evans-Brown M, Kimergård A, McVeigh J, Chandler M, Brandt SD. Is the breast cancer drug tamoxifen being sold as a bodybuilding dietary supplement?, British Medical Journal. 348 (2014) g1476. DOI: $10.1136 /$ bmj.g1476. Available at: https://www.researchgate.net/profile/Jim_Mcveigh/publication/260194844_BODYBUILDING_SUPP LEMENTS Is the breast cancer drug tamoxifen being sold as a bodybuilding dietary supplem ent/links/0deec52fdf77d9685e000000.pdf Accessed 06 July 2017.

Home Office. 2014. Annual Report on the Home Office Forensic Early Warning System (FEWS): A system to identify new psychoactive substances in the UK. Available at: https://www.gov.uk/government/uploads/system/uploads/attachment data/file/344551/2014-08-12 FEWS_Annual Report_Aug_2014__Final_2_.pdf Accessed 06 July 2017.

Gilani F. 2016. Novel psychoactive substances: the rising wave of 'legal highs'. British Journal of General practice. 66 (642): 8-9. DOI: 10.3399/bjgp16X683053.

Guirguis, A., Corkery, J., Stair, J.L., Zloh, M., Kirton, S.B. and Schifano. 2017a. Intended and unintended use of cathinone mixtures. Journal of Human Psychopharmacology: Clinical and Experimental. DOI: 10.1002/hup.2598.

Guirguis A, Girotto S, Berti B, Stair JL. 2017b. Evaluation of two laser sources, 785 and $1064 \mathrm{~nm}$, for the identification of new psychoactive substances using handheld Raman spectroscopy. Forensic Science International. 273: 113-123. DOI: 10.1016/j.forsciint.2017.01.027. 
Guirguis, A. \& Lawrence, M. J. 2017. New psychoactive substances. In: Medicines, Ethics and Practice. The Professional Guide for Pharmacists. (Section 3.5.21). Tang, W. (ed.). 41 ed. UK: Royal Pharmaceutical Society, p. 90-91.

Owen-Bowden J, Fitch C, Hilton C, Lewis J, Ofori-Attah G. 2014. One new drug a week. Why novel psychoactive substances and club drugs need a different response from UK treatment providers. UK:

Royal College Psychiatrists. Available at:

https://www.rcpsych.ac.uk/pdf/FR\%20AP\%2002_Sept2014.pdf Accessed 10 July 2017.

Schifano F, Orsolini L, Papanti GD, Corkery JM. 2015. Novel psychoactive substances of interest for psychiatry. World Psychiatry. 14: 15-26. DOI: 10.1002/wps.20174. Available at: http://onlinelibrary.wiley.com/doi/10.1002/wps.20174/full Accessed 10 July 2017.

Schifano F, Papanti GD, Orsolini L, Corkery JM. 2016. The consequences of drug miuse on postmarketing surveillance. Expert Review of Clinical Pharmacology. 9: 867-871. DOI: $10.1080 / 17512433.2016 .1178571$

TSO (The Stationery Office). 2016. Psychoactive Substances Act 2016. UK: Crown. Available at: http://www.legislation.gov.uk/ukpga/2016/2/pdfs/ukpga_20160002_en.pdf Accessed 06 July 2017.

Rose M, Dargan PI, Norman JC, Flanagan AY. 2015. Novel psychoactive substances: spice, bath salts, and beyond. NetCE, Sacramento, California. Available at:

https://www.netcestudents.com/studypoints.php?courseid=1273\&viewall=true Accessed 05 July 2017.

UNODC. 2017. Market analysis of synthetic drugs. Amphetamine-type stimulants, new psychoactive substances. World drug report 2017. Vienna: United Nations Office on Drugs and Crime. Available at: file://D:/21\%2011\%2016/Documents_NPS/UNODC/UNODC_World\%20drug\%20report\%202017.p df Accessed on 07 August 2017. 